\title{
NO NEEDLE NO SCALPEL VASECTOMY- AN INDIAN EXPERIENCE
}

\author{
Ramachandra Murti Kaza1, Lovenish Bains², Baljit Kaur ${ }^{3}$, Rajesh Arora ${ }^{4}$
}

1 Professor, Department of Surgery, Formerly at Maulana Azad Medical College, New Delhi.

${ }^{2}$ Assistant Professor, Department of Surgery, Maulana Azad Medical College, New Delhi.

3Programme Officer, Department of Family Planning, Government of Punjab.

${ }^{4}$ Clinic Co-ordinator, Men's Clinic.

\section{ABSTRACT}

\section{BACKGROUND}

No Scalpel Vasectomy has led to significant reduction in complications and wider acceptance of vasectomy all over the world. Fear of needle prick during administration of local anaesthesia remains a worry in a subset of the population.

The objective of this study is to compare the techniques of jet injection and needle injection in terms of pain, operating time and complications.

\section{MATERIALS AND METHODS}

The study was conducted in India; 1000 individuals with prior proper consent and thorough counselling were randomised to undergo vasectomy either by jet injection technique or needle injection technique.

\section{RESULTS}

Jet injection group had significant reduction in pain score, operating time and complication rate. There were no needle stick injuries.

\section{CONCLUSION}

No Needle No Scalpel Vasectomy is relatively painless and completely safe method of vasectomy. Jet injector anaesthesia technique is cost effective, time saving method with minimal complications and excellent client satisfaction.

\section{KEYWORDS}

No Scalpel Vasectomy (NSV), No Needle No Scalpel Vasectomy (NNNSV), Vasectomy, Jet Injector, Local Anaesthesia.

HOW TO CITE THIS ARTICLE: Kaza RM, Bains L, Kaur B, et al. No needle no scalpel vasectomy- an Indian experience. J. Evolution Med. Dent. Sci. 2017;6(21):1691-1694, DOI: 10.14260/Jemds/2017/372

\section{BACKGROUND}

Vasectomy is the only permanent method available for male contraception. Introduction of No Scalpel Vasectomy (NSV) in 1973 by Li Shun Qiang has increased the contribution of men in family planning, but is still far less than that by women. World prevalence rate for male and female sterilisation is $2.4 \%$ and $18.9 \%$ respectively, whereas figures for India are $1.1 \%$ and $35.8 \%$ respectively. ${ }^{1}$ Acceptance of vasectomy in India increased as evidenced by increase in number of vasectomies from $0.7 \%$ in 1997 to $3 \%$ in $2003 .{ }^{2} \mathrm{NSV}$ has become the gold standard of male sterilisation. The standard method involves ligation and excision of a $1 \mathrm{~cm}$ segment of vas with fascial interposition. Local anaesthesia in this procedure involves raising an intradermal wheal at the site of fixation of vas and injection of lignocaine $2 \%$ perivasally to block both the vasa. This blind method of injecting local anaesthetic is not free of complications like injury to testicular artery leading to bleeding and haematoma or at times testicular atrophy and intravascular injection leading to systemic intoxication. ${ }^{3,4}$ No needle jet injection technique has been in use since the last decade and has been found

Financial or Other, Competing Interest: None.

Submission 20-12-2016, Peer Review 26-02-2017,

Acceptance 04-03-2017, Published 13-03-2017.

Corresponding Author:

Dr. Ramachandra Murti Kaza,

\#9/301, East End Apartments,

Mayur Vihar Phase-I Extension,

New Delhi-110096

E-mail: kazarcm@gmail.com

DOI: $10.14260 /$ jemds $/ 2017 / 372$ simple and safe technique with immediate onset of profound anaesthesia and high patient satisfaction as reflected by low pain scores. $5,6,7,8$ The present study was conducted to evaluate efficacy of jet injection for vasectomy in Indian patients and to compare it with needle anaesthesia.

\section{MATERIALS AND METHODS}

This study was conducted in Department of Surgery and Department of Family Planning, Maulana Azad Medical College and Lok Nayak Hospital, New Delhi and Civil Hospital, Amritsar, Punjab. Inclusion criteria were set according to the national standards of Government of India, i.e. all clients who were between 21 to 60 years of age group had at least one living child and who had voluntarily adopted this method of contraception were included in our study. Clients with history of diabetes, previous scrotal surgery, hernia surgery, filarial thickening of skin and filarial funiculitis and any other scrotal pathology, which would make isolation of vas difficult were excluded from the study. After thorough counselling and fully informed consent about both the normal and jet injection techniques; 1000 clients were randomised into two groups. Group A underwent Jet Injector anaesthesia (JI) for NSV and Group B underwent Needle Injection (NI) anaesthesia for NSV. Both the groups were compared in terms of effectiveness of anaesthesia, pain during application of local anaesthetic, operating time and complications like formation of haematoma of the cord.

Jet injector is based on the principle of ejecting microdroplets with high-velocity through an orifice. The drug is deposited in the tissues either due to skin 'failure' or flow 
through the skin or both. The velocity of the jet is directly proportional to pressure ( $p$ ) in the nozzle and is inversely proportional to density $(\rho)$ of the liquid. It is calculated by the formula:

$$
\mathrm{V}=(2 \mathrm{p} / \rho)^{1 / 2}
$$

The velocity is also affected by diameter of the orifice, turbulence and friction. ${ }^{9}$

Jet injector is a nearly painless, rapid, needle-free method of drug administration. Since its introduction nearly 3 decades before, it has been successfully tested and used for application of local anaesthesia in dentistry, gynaecology and podiatry as well as other medical applications ${ }^{10-14}$ for intradermal and subcutaneous lignocaine administration before IV catheterisation ${ }^{11}$ and for giving digital blocks. ${ }^{14}$ Other uses include subcutaneous insulin, local anaesthesia for minor procedures and biopsies, and medication delivery. There are different devices commercially available for jet injection technique. We used MadaJet XL® jet injector for our study (Figure 1). Both oblique and straight spacer are available, oblique one JI may help in better visualisation of the spacer tip for delivering the anaesthesia; however, it remains a matter of personal choice.

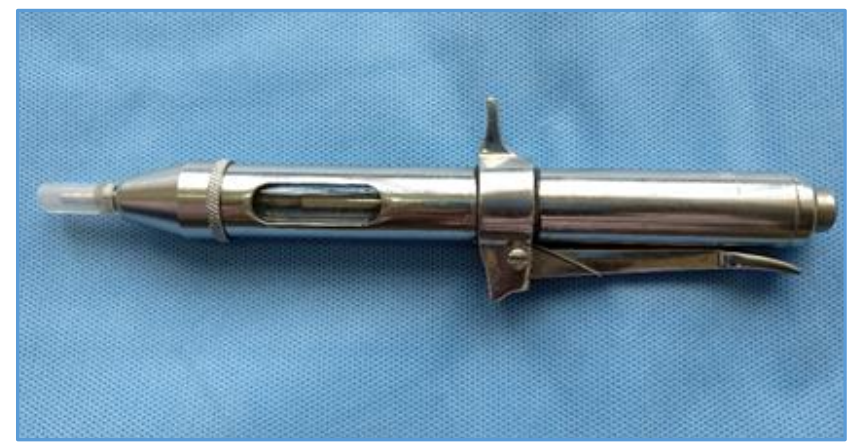

Figure 1. Jet Injector MadaJet XL (Reproduced with Permission)

Madajet XL requires at least $50 \%$ less volume of anaesthetic to achieve same level of anaesthesia. This advantage is the result of the particle size of the anaesthetic agent, which enters the tissue. In contrast to pooling of medication by syringe/needle, MadaJet XL disperses the medication into tissue in tiny droplets producing almost immediate effect (about 1 millisecond) from the absorption by myelin sheath covering nerve tissue. ${ }^{15}$

The pressure generated by MadaJet can be set at different points. The recommended pressure for anaesthetising vas is 4 ounces per foot-pound and even at this pressure there is chance that drug may exit through posterior scrotal skin and enter the operator's skin. ${ }^{16}$ An impermeable finger protector over the supporting finger behind the vas may be required to prevent accidental injection of anaesthesia through the scrotum into the surgeon's finger. Alternatively, adhesive tape may be put upon the middle finger before gloving. Drug penetrates into tissues through a depth of $6 \mathrm{~mm}$ in an inverted cone shaped distribution and distributes 0.5 to $0.6 \mathrm{cms}$ circularly from the point of contact (Figure 2). Amount of drug released per discharge is $0.1 \mathrm{~mL} .^{15,16}$

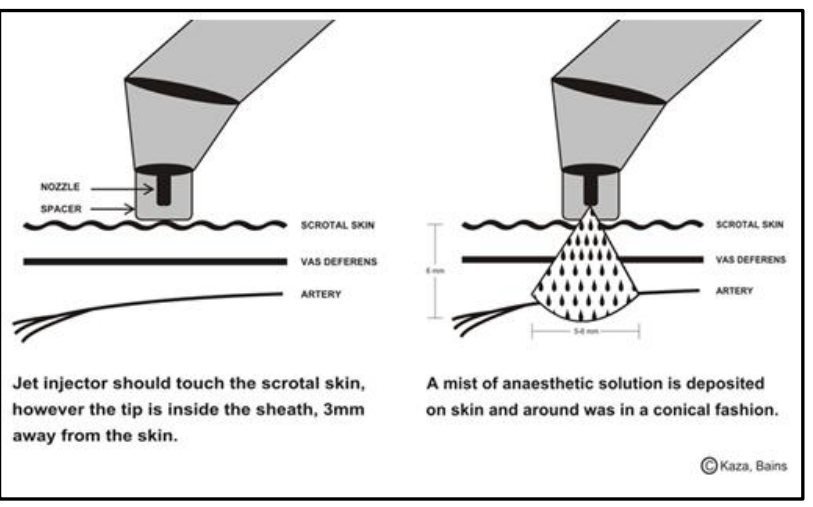

Figure 2. Jet Injector-Mechanism of Functioning

The onset of anaesthesia is almost immediate, within 10 to 20 seconds. Patients experiences mild discomfort of a pinch, not unlike that of a rubber band. The anaesthetic mist is rapidly absorbed throughout tissue around the vas with much less trauma and the injection sites are identified by a pinpoint area of blanching. ${ }^{6}$ Proper disinfection of Jet injector is a must.

\section{The Procedure}

For both the groups, standard three fingered technique for isolation and fixation of vas was used. With the surgeon standing on right side, right vas was palpated and manipulated with the left hand to a superficial position under the median raphe at the junction of upper and middle third of the scrotum and it was held firmly using the three finger technique.

\section{Jet Injection Technique}

After fixing the vas along the median raphe at the junction of upper $1 / 3$ rd and lower 2/3rd for Group A, the tip of the jet injector filled with $2 \%$ plain lignocaine (without adrenaline) was placed over the vas with gentle pressure (Figure 3).

Then it was fired three times sequentially, proceeding from proximal to distal $2-3 \mathrm{~mm}$ apart. The jet penetrates the skin at a single puncture site, which may be visible as a pinpoint mark. Sometimes, a tiny drop of blood may appear at the site of injection. Same process was repeated on the opposite side.

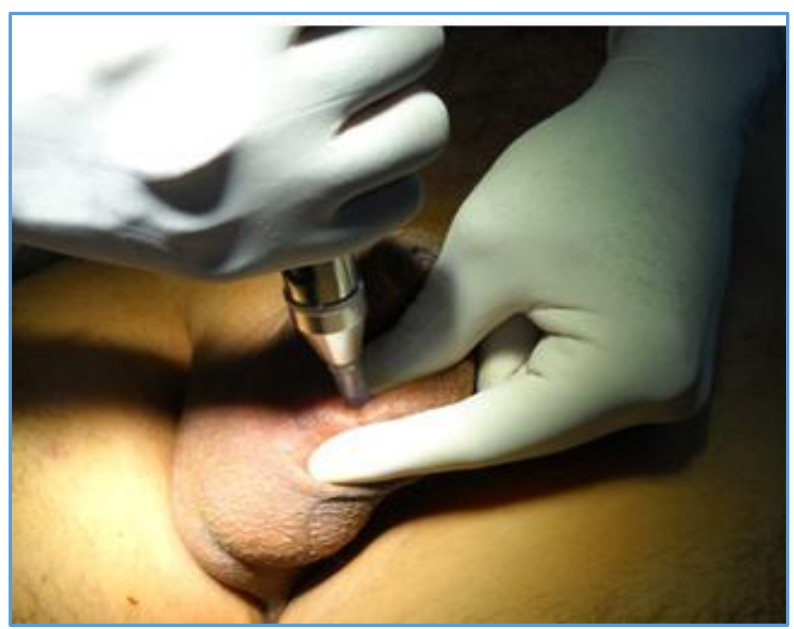

Figure 3. Application of Jet Injector to Site of Procedure on Scrotal Skin 


\section{Needle Injection Technique}

A superficial skin wheal was raised with $2 \%$ plain lignocaine using a 24-G needle. The needle was advanced in the perivasal plane (alongside the vas) toward the external inguinal ring and about $2 \mathrm{~mL}$ of plain lignocaine (without adrenaline) was injected at one site without withdrawing the needle to achieve vasal block. The left vas was also anaesthetised using the same technique through the same puncture. The skin wheal was pinched to reduce the local oedema.

After the completion of the procedure, patients were asked to complete a Visual Analogue Scale (VAS) questionnaire. Information regarding pain during injection by needle or jet injector and subsequent pain of vasectomy were documented on two visual analogue scales separately.

\section{DISCUSSION}

NSV is the gold standard of male sterilisation. ${ }^{17}$ The conventional method involves ligation and excision with fascial interposition through two incisions of $2 \mathrm{~cm}$ or a single midline incision. The standard NSV method involves a single midline puncture of $2 \mathrm{~mm}$ with excision of vas and fascial interposition. Local anaesthesia in NSV procedure involves injection of lignocaine $2 \%$ along the vas deferens and raising an intradermal wheal at the site of fixation of vas. The vasal injection is given deep to external spermatic fascia, but superficial to internal spermatic fascia which encloses testicular arteries and veins. ${ }^{2} \mathrm{~A}$ blindly performed block may be inefficient in inexperienced hands and bears its own potential risks like injury to testicular artery leading to bleeding and haematoma or at times testicular atrophy and inadvertent intravascular injection leading to systemic intoxication. ${ }^{3,4}$ Many learn the procedure by trial and error during or after their residency training. Kendrick and Colleagues have shown how vasectomy performed by inexperienced hands leads to an increased incidence of complications such as bleeding, haematoma and infection. 4,18

Vasectomy is a surgical procedure voluntarily sought by a normal client to end his fertility and hence the need for painfree procedure and eliminating complications are most important factors for making a sterilisation procedure attractive to clients. Move from Conventional vasectomy to no scalpel vasectomy improved client acceptance by almost tenfold. ${ }^{2}$ In order to make the procedure non-invasive, the world has experimented with 'high intensity focused ultrasound ablation of the vas deferens'19 and 'non-invasive laser coagulation of the vas deferens.'20 However, these studies have been done in limited canine models and carry the risks of scrotal burns, collateral thermal damage to surrounding structures and also laser adds costs significantly to procedure. Future studies may pave way for non-invasive vas occlusion or vas ablation.

JI technique has been introduced successfully for procedural anaesthesia. No-needle anaesthesia with jet injection is a new technique to deliver rapid onset of profound local anaesthesia to the vasectomy patient. It is a safe and virtually painless anaesthetic application. Additionally, it reduces the risk of needle-stick injury and limits syringe waste management. The anaesthetic solution is sprayed through the skin and around vas using high pressurised injector, which has been described as gentle snap of rubber band against the scrotal skin. In 2001, Wilson first described no needle jet injection technique using MadaJet ${ }^{\circledR}$ injection system for vasectomy. ${ }^{5}$ Weiss and Li modified and refined jet injection technique for NSV discussed by Wilson in his report. ${ }^{6}$ According to their experience, Jet injection of anaesthetic for NSV is very simple and safe technique with immediate onset of profound anaesthesia and high patient satisfaction as reflected by low pain scores. 5,6

The mean age of the clients in our study was 35.64 years in JI Group and was 35.85 years in NI Group. The average visual analog pain score for vasectomy after jet injector anaesthesia was 1.43 of 10 (range 0 - 6), while after needle anaesthesia it was 4.39 of 10 (range $0-8$ ). This difference was statistically significant ( $p=0.0001)$ when compared using student's ' $t$ ' test. White and Maatman ${ }^{7}$ had reported an average pain score of 1.68 of 10 (range 0 - 6) after jet injector and 1.86 of 10 (range 0 - 9) after needle injection anaesthesia for vasectomy. They did not find this difference to be statistically significant ( $\mathrm{p}=$ 0.66 ). This difference could have been due to the fact that they had assessed effect of jet injector and needle anaesthesia on the same subject. Wiess and $\mathrm{Li}^{6}$ had reported an average pain score of 0.66 of 10 (range 0 - 6.6) for vasectomy after jet injector anaesthesia.

The average operating time for JI Group was 6.84 mins (range 5 - 11 mins), whereas it was 9.11 mins (range 5 - 11 mins) for NI Group. This difference was statistically significant $(p=0.0001)$ when compared using student's ' $t$ ' test. There is average gain of 2.27 mins per case, which can be very significant in our setup where hundreds of vasectomies are performed in camps. This difference could have been due to the mandatory time required for the action of local anaesthetic.

None of the clients in JI Group had developed complications, whereas 17 clients in NI Group developed complications. This difference was statistically significant when compared using Pearson Chi-Square test (0.0001). Most common complication was persistent mild-to-moderate postoperative pain (11/17) requiring additional analgesic and 6/17 had developed cord haematoma. Similarly, none of the clients in JI Group developed anaphylaxis, but 2 clients in NI Group had anaphylaxis.

During this study, it was also observed that more amount of local anaesthetic was required in the needle injection group. JI Group required just $0.6 \mathrm{~mL}$ of local anaesthetic, whereas the NI Group required $5 \mathrm{~mL}$ per patient. Less volume of drug used, no need for needle and syringe leads to cost effectiveness; however, initial cost of jet injector is to be considered. None of our surgeons or assistants had needle stick injuries.

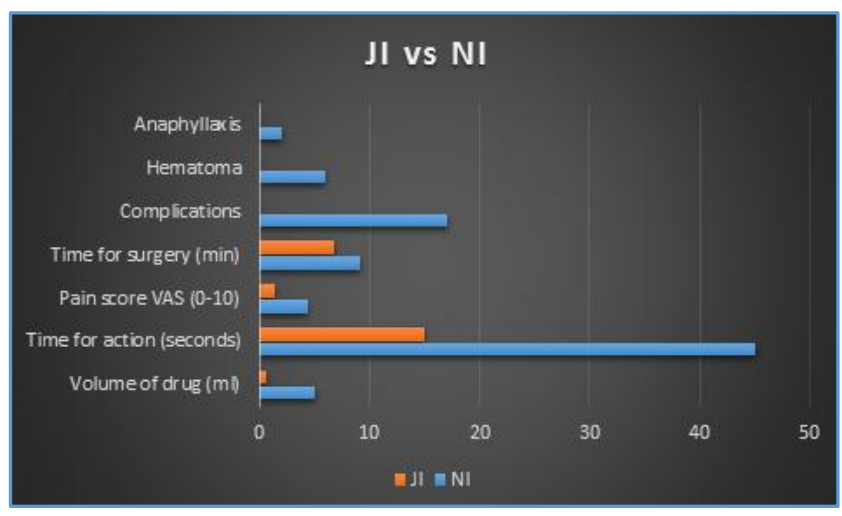

Graph 1. Comparison Outcomes of Jet Injection vs Needle Injection

The world has seen 10 -fold reduction in complications with introduction of NSV compared to conventional vasectomy. ${ }^{21} \mathrm{JI}$ has practically no complications so far. $.5,6,7,8$ 
Men have feared vasectomy for various reasons, one among them is fear of the needle. ${ }^{6} \mathrm{JI}$ technique has allayed the fear associated with needle puncture in vasectomy and gaining wide popularity and acceptance. It is expected to boost the acceptance of male sterilisation again in conjunction with NSV. NNNSV is simple, safe, effective technique with high patient satisfaction. $6,7,8$

\section{CONCLUSION}

In conclusion, No Needle No Scalpel Vasectomy using jet injector has the following advantages:

1. Use of jet injector significantly reduces the mean operation time; hence, more number of cases can be performed on a particular day in camps.

2. Low pain scores for the procedure as a whole.

3. The quantity and cost of anaesthesia is far less as compared to NI anaesthesia.

4. It is cost effective.

5. Less chance of hypersensitivity.

6. No chance of needle stick injury to surgeon.

7. Easier fixation of vas as no skin wheal is raised.

8. No needle associated complications in patients.

9. Reduces fear - increases acceptance.

10. Excellent patient satisfaction.

NNNSV is relatively painless and completely safe method of vasectomy. Jet injector anaesthesia technique is the most cost effective and time saving method for application of local anaesthetic with excellent client satisfaction.

No scalpel vasectomy gave a boost to male participation. NSNNV will further enhance this.

\section{REFERENCES}

[1] World Contraceptive Patterns 2013. UN, New York: United nations department of economic and social Affairs, population division. http://www.un.org/ en/development/desa/population/publications/pdf/f amily/worldContraceptivePatternsWallChart2013.pdf

[2] Kaza RC. No-scalpel vasectomy: an overview. Journal of the Indian Medical Association 2006;104(3):129-30.

[3] Li PS, Li SQ, Schlegel PN, et al. External spermatic sheath injection for vasal nerve block. Urology 1992;39(2):173-6.

[4] Goldstein M, Young GPH, Einer-Jensen N. Testicular artery damage due to infiltration with a fine gauge needle: experimental evidence suggesting that blind cord block should be abandoned. Surg Forum 1983;24:653-6.

[5] Wilson CL. No-needle anaesthetic for no-scalpel vasectomy. Am Fam Physician 2001;63(7):1295.
[6] Weiss RS, Li PS. No-needle jet anaesthetic technique for no-scalpel vasectomy. J Urol 2005;173(5):1677-80.

[7] White MA, Maatman TJ. Comparative analysis of effectiveness of two local anesthetic techniques in men undergoing no-scalpel vasectomy. Urology 2007;70(6):1187-9.

[8] Monoski MA, Li PS, Baum N, et al. No-scalpel, no-needle vasectomy. Urology 2006;68(1):9-14.

[9] Florence AT, Attwood D. Physicochemical principles of pharmacy. 4th edn. London, Pharmaceutical Press 2006:365-6.

[10] Ellis GL, Owens A. The efficacy and acceptability of using a jet injector in performing digital blocks. Am J Emerg Med 1993;11(6):648-50.

[11] Bennet J, Nichols F, Rosenblum M, et al. Subcutaneous administration of midazolam: a comparison of the bioject jet injector with the conventional syringe and needle. J Oral Maxillofac Surg 1998;56(11):1249-54.

[12] Munshi AK, Hegde A, Bashir N. Clinical evaluation of the efficacy of anaesthesia and patient preference using the needle-less jet syringe in pediatric dental practice. J Clin Pediatr Dent 2001;25(2):131-6.

[13] Zsigmond EK, Darby P, Koenig HM, et al. Painless intravenous catheterization by intradermal jet injection of lidocaine: a randomized trial. J Clin Anesth 1999;11(2):87-94.

[14] Cooper JA, Bromley LM, Baranowski AP, et al. Evaluation of a needle free injection system for local anaesthesia prior to venous cannulation. Anaesthesia 2000;55(3):247-50.

[15] No needle jet injector podiatry presentation, advanced meditech international, Inc. Flushing New York 11373 USA. http://www.ameditech.com/ medinfo/JetInjectorPodiatry03052005.pdf

[16] Weiss RS. Re: no-needle jet anesthetic technique for no-scalpel vasectomy. J Urol 2005;176(2):842-3.

[17] Labrecque M, Dufresne C, Barone MA, et al. Vasectomy surgical techniques: a systematic review. BMC Med 2004;2:21.

[18] Kendrick J, Gonzales B, Huber DH, et al. Complications of vasectomies in the United States. J Fam Prac 1987;25(3):245-8.

[19] Roberts WW, Chan DY, Fried NM, et al. High intensity focused ultrasound ablation of the vas deferens in a canine model. J Urol 2002;167(6):2613-7.

[20] Cilip CM, Jarow JP, Fried NM. Noninvasive laser vasectomy: preliminary ex vivo tissue studies. Lasers Surg Med 2009;41(3):203-7.

[21] Nirathpongporn A, Huber DH, Krieger JN. No-scalpel vasectomy at the king's birthday vasectomy festival. Lancet 1990;335(8694):894-5. 